\title{
On the finite line source problem in diffusion theory
}

\author{
Mikkelsen, T.; Troen, I.; Larsen, Søren Ejling
}

Publication date:

1981

Document Version

Publisher's PDF, also known as Version of record

Link back to DTU Orbit

Citation (APA):

Mikkelsen, T., Troen, I., \& Larsen, S. E. (1981). On the finite line source problem in diffusion theory. Ris $\varnothing$ National Laboratory. Risø-M No. 2309

\section{General rights}

Copyright and moral rights for the publications made accessible in the public portal are retained by the authors and/or other copyright owners and it is a condition of accessing publications that users recognise and abide by the legal requirements associated with these rights.

- Users may download and print one copy of any publication from the public portal for the purpose of private study or research.

- You may not further distribute the material or use it for any profit-making activity or commercial gain

- You may freely distribute the URL identifying the publication in the public portal

If you believe that this document breaches copyright please contact us providing details, and we will remove access to the work immediately and investigate your claim. 
RISQ-M-2309

ON THE FINITE LINE SOURCE PROBLEM IN DIFFUSION THEORY

T. Mikkelsen, I. Troen and S.E. Larsen

Abstract. A simple formula for calculating dispersion from a continuous finite line source, placed at right angles to the mean wind direction, is derived on the basis of statistical theory. Comparison is made with the virtual source soncept usually used and this is shown to be correct only in the limit where the virtual time $l a g T_{V}$ is small compared to the timescale of the turbulence $t_{1}$.

UDC $533.15: 551.511$

September 1981

Risø National Laboratory, LK-4000 Roskilde, Denmart. 
ISBN 87-550-0792-9

ISSN 0418-6435

Riso Repro 1981 
CONTENTS

1. INTRODUCTION $\ldots \ldots \ldots \ldots \ldots \ldots \ldots \ldots \ldots \ldots \ldots \ldots \ldots \ldots \ldots \ldots \ldots \ldots$

2. THEORY ................................. 6

3. EXAMPLE WITH AN EXPONENTIAL LAGRANGIAN AUTO-

CORRELATION FUNCTION $\ldots \ldots \ldots \ldots \ldots \ldots \ldots \ldots \ldots \ldots \ldots \ldots \ldots \ldots 11$

4. CONCLUSION ............................... 13

5. REFERENCES $\ldots \ldots \ldots \ldots \ldots \ldots \ldots \ldots \ldots \ldots \ldots \ldots \ldots \ldots \ldots \ldots \ldots \ldots$

6. FIGURE ..................................... 15 

1. INTRODUCTION

In investigating the dispersion from a continuous line source of finite length, placed at right angles to the mean wind direction, the virtual source concept is commonly used. A "virtual" point source is placed upwind from the location of the line source so that its plume width at the position of the line source equals the initial spread of the line source, Slade (1968). However, this thod has, as it will be shown, no theoretical justification when the extension of the source becomes comparable to or bigger than the length scale of the dispersing turbulence.

For a finite line source of uniform source density $q(\mathrm{~kg} / \mathrm{sec} \mathrm{m})$, sutton (1932) derived a solution for the concentration field showing the socalled "edge effect". He considered a line source as being made up of an infinity of small Gaussian point sources, the emission of which per unit length was $q$. Next, the concentration distribution $c$ at a down wind position $x$ from the line source was calculated by a superposition of the contribution from each of the individual sources, yielding the result

$$
c=\frac{2 q}{\sqrt{2 \pi} \sigma_{z} u} \cdot \exp \left(-\frac{1}{2}\left(\frac{H}{\sigma_{z}}\right)^{2}\right) \cdot \int_{p 1}^{2} \frac{1}{\sqrt{2 \pi}} \exp \left(-\frac{1}{2} p^{2}\right) d p
$$

where $p_{1}=\frac{y_{1}}{\sigma_{y}}$ and $p_{2}=\frac{y_{2}}{\sigma_{y}}$.

$H$ is the effective height of release, i the mean wind, $\sigma_{y}(x)$ and $\sigma_{z}(x)$ the lateral and the vertical dispersion coefficients for the point source respectively, and $y_{1}$ and $y_{2}$ the upper and the lower lateral bounds of the line source at $x=0$. 


\section{THEORY}

The idea outlined above will be generalized to situations where the strength of the line source, though constant in time, varies with the lateral position of emission $Y_{0}$ as specified by the source distribution function $f\left(Y_{0}\right)$ as show in Fig. 1 .

In the following, we can for convenience and without loss of generality assume the source distribution function $f\left(y_{0}\right)$ to

a) be normalized

$$
\int_{-\infty}^{\infty} f\left(y_{0}\right) d y_{0}=1
$$

b) be centered with respect to $Y_{0}=0$

$$
\int_{-\infty}^{\infty} y_{0} f\left(y_{0}\right) d y_{0}=0
$$

c) define a second order moment $\Sigma$ by

$$
\int_{-\infty}^{\infty} y_{0}^{2} f\left(y_{0}\right) d y_{0}=\Sigma^{2}
$$

In order to be able to calculate the resulting dispersion of the line source, we consider the line source as being made up of an infinity of many identical point sources, distributed continuously along the line $y_{0}$ with density $f\left(y_{0}\right)$.

From each of these point sources, particles are released simultaneously into a field of homogeneous and stationary turbulence at $t$ ime $t=0$. As shown in Fig. 1 , the position of the individual particles, relative to the centerline $y_{0}=0$, can as well be expressed in terms of the particles initial displacement $y_{0}$, and the subsequent stochastic displacement relative to this, $y(t)$. For each of the simultaneous released particles this position reads 


$$
y(t)=y_{0}+\bar{y}(t)
$$

First we calculate the mean position of the simultaneous released particles at anbitrary diffusion tine $t \geq 0$. Cailing this mean position $Y(t)$, we formally get

$$
\langle Y(t)\rangle=\left\langle\int_{-\infty}^{\infty} y(t) f\left(y_{0}\right) d y_{0}\right\rangle
$$

The brackets denote ensemble averaging and the source density function $f\left(y_{0}\right)$ determines the relative number of particles that are released from the point source located at the position $Y_{0}$.

In order to proceed, we note that $\dot{y}(0)=0$ since $y_{0}$, and that, with the assumed homogeneity of the turbulence, we will have $\langle\dot{y}(t)\rangle=0$. Further, as a consequence of the stationarity assumed, ensemble averages can be repiaced by time averages, provided that the averaging time is sufficiently long. This implies averaging over several Langrangian time scales $t_{1}$.

By inserting $y(t)$ from Eq. (5) into Eq. (6) we get, on the basis of Eq. (3) and the fact that $\langle y(t)\rangle=0$, the following result

$$
\begin{aligned}
\langle Y(t)\rangle= & \left\langle\int_{-\infty}^{\infty} Y_{0} f\left(Y_{0}\right) d y_{0}\right\rangle \\
& +\int_{-\infty}^{\infty}\langle\tilde{y}(t)\rangle f\left(Y_{0}\right) d y_{0}=0
\end{aligned}
$$

which simply shows that the mean displacement of the particles, relative to the fixed frame of reference $y_{0}=0$, is zero.

Formally, we next define the aispersion $\left\langle D^{2}(t)\right\rangle$ of the line source in terms of the square of the position relative to the ensemble mean $\langle Y(t)\rangle$ of the simultaneous released particles, after a diffusion time $t$

$$
\left\langle D^{2}(t)\right\rangle=\left\langle\int_{-\infty}^{\infty}(y(t)-\langle Y(t)\rangle)^{2} f\left(y_{0}\right) d y_{0}\right\rangle
$$


Even though we consider the simultancous release of many particles, one should not confuse the problea with that of relative or two-particle diffusion since here, all displacements are * referred to the fixed frame of reference $\langle Y(t)\rangle$ which is coincident with $Y_{0}=0$.

By use of Eq. (5), Eq. (8) takes the form

$$
\left\langle D^{2}(t)\right\rangle=\left\langle\int_{-\infty}^{\infty}\left(y_{0}^{2}+2 y_{0} \tilde{Y}(t)+\tilde{y}^{2}(t)\right) \cdot E\left(y_{0}\right) d y_{0}\right\rangle
$$

The first term on the right hand side equals by definition $\Sigma^{2}$. As a consequence of the lateral homogeneity, the second term is zero because of

$$
\left\langle\int_{-\infty}^{\infty} 2 y_{0} \tilde{y}(t) f\left(y_{0}\right) d y_{0}\right\rangle=\langle\tilde{y}(t)\rangle \int_{-\infty}^{\infty} 2 y_{0} f\left(y_{0}\right) d y_{0}=0
$$

The last term of Eq. (9) can be written

$$
\int_{-\infty}^{\infty}\left\langle\bar{y}^{2}(t)\right\rangle f\left(y_{0}\right) d y_{0}=\left\langle\bar{y}^{2}(t)\right\rangle
$$

since $\left\langle\tilde{y}^{2}(t)\right\rangle$, due to the assumed lateral homogeneity, is independent of Yo.

The resulting expression for the line source dispersion now reads

$$
\left\langle D^{2}(t)\right\rangle=\Sigma^{2}+\left\langle\tilde{y}^{2}(t)\right\rangle
$$

This is quite a notable result since it does not depend on the specific form of the line source distribution function $f\left(y_{0}\right)$, nor on the speific concentration distribution of the individual sources.

For dispersion of individual point sources in a field of homogeneous and stationary turbulence the statistical theory, Taylor (1921), yields the familiar result, applicable for the 
last tera in eq. $(: 2)$

$$
\frac{1}{2} \frac{d\left\langle\tilde{y}^{2}\right\rangle}{d t}=\left\langle v^{-2}\right\rangle \int_{0}^{t} p_{1}(\xi) d \xi
$$

Here, $t$ is travel time $(=x / \bar{u}),\left\langle v^{\prime} 2\right\rangle$ is the variance of the cross-wind turbulent fluctuations and $p_{1}$ is the Lagrangian velocity correlation function. The near field $\left(t<<t_{1}\right)$ and the far field $\left(t>>t_{1}\right)$ limits of the spread are, respectively

$$
\begin{aligned}
& \lim _{t \rightarrow 0}\left\langle\bar{y}^{2}\right\rangle=\left\langle v^{\cdot 2}\right\rangle t^{2} \\
& \lim _{t \rightarrow 0}\left\langle\bar{y}^{2}\right\rangle=2\left\langle v^{\cdot 2}\right\rangle t_{1} t
\end{aligned}
$$

By inserting the near field limit of Eq. (14) into Eq. (12), a second order expansion for small t gives

$$
\left\langle D^{2}(t)\right\rangle^{\frac{1}{2}}=\varepsilon\left(1+\frac{\left\langle v^{\cdot 2}\right\rangle}{\tau^{2}} t^{2}\right)
$$

In contrast to the virtual source solution, we here find that the dispersion calculated on the basis of Eq. (12) implies a parabolically initial stage of dispersion, with zero slope for small travel times, i.e.

$$
\lim _{t \rightarrow 0} \frac{d}{d t}\left\langle D^{2}(t)\right\rangle=0
$$

The result in Eq. (12) has a counterpart in the discipline of calculating moments of inertia in mechanics. If the moment of inertia of a solid body around an axis $T_{0}$ through its center of mass is given by $I_{0}$. then. the moment of inertia $I$ about an axis translated the distance $\Delta l$ from $T_{0}$ is given by "the parallel axis theorem"

$$
I=I_{\Delta \ell}+I_{0}
$$


where $I_{A l}$ is the moment of inertia of the body's cotal ass in with respect to the translation al, i.e. I 12 a $(\Delta L)^{2}$. Aralogy of Eq. (14) with Eq. (12) becoms clear when point source dispersion $\left\langle\bar{y}^{2}(t)\right\rangle$ is associated with $I_{0}$ and the dispersion of the distributed point sources center of ass $y_{0}$ is associaced with 12. $I$ in Eq. (12) then iepresents an effuctive translation of center of mas deff calculated on the basis of the source distribution function $f\left(y_{0}\right)$.

In case we want to calculate not only the dispersion associated with an extended source but also want to gain knowledge of the resulting concentration distribution as function of travel tia and lateral displacement $c\left(Y_{0}, t\right)$, will have to deal with the convolution integral

$$
c\left(y_{0}, t\right)=\int_{-\infty}^{\infty} g(t, \bar{y}) \cdot f\left(\bar{y}-y_{0}\right) d \bar{y}
$$

where $g(t, \bar{y})$ represents the normalized concentration distribution function of the individual point sources. Eq. (1) constitutes a special case of Eq. (19) where $f$ is a uniforn dijtribution with upper and lower linits, $y_{2}$ and $y_{1}$, respecively, and $g(t, \bar{y})$ is a Gaussian distributio. In Fig. 2 is show a sequence of plots of c calculated on the basis of Eq. (18) for the case $y_{2}=-y_{1}=1$ i. Concentration distributions for subsequent ratios of the point source dispersion, $\langle\bar{y} \cdot 2(t)\rangle\rangle=0$, to the initial source width, $l=\sqrt{12} \varepsilon$, is shom. The transition from the initial rectangular distribution to the ultimative Gaussian distribution is obviously illustrated.

Another special case of $\mathrm{Eq} .(18)$ appears when not on $1 \mathrm{y} g(t, \bar{Y})$ but also $f\left(y_{0}\right)$ is Gaussian distributed. In this case it is com monly known that also $c\left(Y_{0}, t\right)$ becoms a Gaussian distributjon (for all travel times). Purthermore, the variance simply becomes the sum of the variances of $g(t, Y)$ and $f\left(y_{0}\right)$, in accordance with Eq. (12).

We will next show that Eq. (12) in general is a direct consequence of Eq. (18). The second moment of c(yo,t) is by definition 


$$
\left\langle D^{2}(t)\right\rangle=\int_{-\infty}^{\infty} y_{0}^{2} \int_{-\infty}^{0} z(t, \bar{y}) \cdot t\left(q-y_{0}\right) d q d y
$$

Dy use of the substitution $\hat{y}=\bar{q}-Y_{0}$. this becoms

$$
\begin{aligned}
& \left\langle D^{2}(t)\right\rangle=\int_{-\infty}^{\infty}(\bar{y}-\bar{y})^{2} g(t, \bar{y}) \cdot t(\bar{y}) d \bar{y} d \bar{y} \\
& =\int_{-0}^{\infty} \dot{y}^{2} g(t, \bar{y}) d \bar{y}+\int_{-\infty}^{\infty} \bar{y}^{2} f(\bar{y}) d \bar{y} \\
& -2 \iint \bar{y} g(t . \bar{Y}) \in(\bar{y}) d \bar{y} \hat{y}
\end{aligned}
$$

The last term equals zero on basis of Eq. (3) and Eq. (12) =emains.

3. EXAMPLE WITH AN EXPONENTIAL LAGRAMGAN AUTOCORRELATION PUnction

The precise form of the Lagrangian autocortelation coefficient $p_{1}$ in Eq. (13) is not important when we investigate the general iaplications of Eq. (12) and for convenience we can assume an exponential form. Also, this form gives a reasonable fit to most observed pl curves, Pasquill (1974). By integration of Eq. (13) with $M_{1}(\xi)=\exp \left(-\varepsilon / t_{1}\right)$ and defining $t=t / t_{1}$ and a $=\left(\left\langle\dot{y}^{2}(t)\right| /\left(\left\langle v^{2}\right) t_{1}\right)\right.$, we have for the dispersion from a point source

$$
1 a^{2}=\tau+\exp (-\tau)-1
$$

We can with this compare the line source dispersion $(D f(t)$; of eq. (12) with the virtual source approach.

The virtual source dispersion $\left\langle D_{V}^{2}(t)\right\rangle$ is through Eq. (21) given by 


$$
\frac{1}{2} \alpha_{V}^{2}=\left(\tau+\bar{T}_{V}\right)+\exp \left(-\left(\tau+\bar{T}_{V}\right)\right)-1
$$

where $x_{V}^{2}=\left\langle D_{V}^{2}(t)\right\rangle /\left\langle v^{\prime 2}\right\rangle t_{I}^{2}$ and where the initial time lag $\dot{\mathrm{T}}_{\mathrm{V}}=\mathrm{T}_{\mathrm{V}} / \mathrm{t}_{1}$ is defined through the equation

$$
\frac{1}{2} \Sigma \cdot 2=\dot{T}_{V}+\exp \left(-\dot{T}_{V}\right)-1
$$

$\Sigma^{\prime} 2$, the normalized second moment of the source distribution is here defined by $\Sigma^{\prime}=\Sigma /\left\langle v^{\prime}\right\rangle^{\frac{1}{2}} \cdot t_{1}$.

The statistical model for the line source gives from Eq. (12)

$$
\frac{1}{2} a_{L}^{2}=\frac{1}{2} \Sigma^{2}+\frac{1}{2} a^{2}
$$

where $a_{L}^{2}=\left\langle D_{L}^{2}(t)\right\rangle /\left\langle v^{\prime 2}\right\rangle t_{1}^{2}$. The difference in dispersion of the two methods $\frac{1}{2} d^{2}=\frac{1}{2} \alpha_{V}^{2}-\frac{1}{2} \alpha_{L}^{2}$ is

$$
\frac{1}{2} d^{2}=\tilde{T}_{V}-\frac{1}{2} \Sigma^{2}+\operatorname{ex} \tau(-\tau)\left\{\exp \left(-\tilde{T}_{V}\right)-1\right\}
$$

The limits for the difference for small and large travel times are, respectively

$$
\begin{aligned}
& \lim _{\tau \rightarrow 0} \frac{1}{r} d^{\prime} 2=0 \\
& \lim _{\tau \rightarrow \infty} \frac{1}{2} d^{\prime 2}=\frac{1}{2} \Sigma \cdot 2-\tilde{T}_{V}=\exp \left(-\tilde{T}_{V}\right)-1
\end{aligned}
$$

Writing in dimensional form the far field limit error, we finally get

$$
\lim _{t \rightarrow \infty}\left(\left\langle D_{V}^{2}\right\rangle-\left\langle D_{L}^{2}\right\rangle\right)=2\left\langle v^{\cdot} 2\right\rangle^{\frac{1}{2} t_{1}}\left\{1-\exp \left(-\frac{T_{V}}{t_{1}}\right)\right\}
$$

We see that the virtual source approach only gives the correct answer when $T_{V}<t_{I}$.

Fig. 3 shows a plot of $\frac{1}{2} \alpha_{V}^{2}$ and $\frac{1}{2} \alpha_{L}^{2}$ for the case where $\Sigma^{\prime}=1$. The paravolic behaviour of $\frac{1}{2} a_{L}^{2}$ for small travel times is clearly recognized. The maximum relative error witn the virtual source approach is found at $\tau=1$ and is this case of the order of 208 . 
Not much experimentally evidence exists on the finite line source problem. From dispersion behind buildings and volume sources as such, slade (1968) proposes empirical dispersion formulae of a form equivalent to $\mathrm{Eq}$. (12)

$$
\begin{aligned}
& D_{y}^{2}=C A / \pi+\sigma_{y}^{2} \\
& D_{z}^{2}=C A / \pi+\sigma_{z}^{2}
\end{aligned}
$$

$D_{y}{ }^{2}$ and $D_{z}{ }^{2}$ are here, respectively, the effective lateral and vertical dispersion behind a building of area $A, C$ is a correction factor between 0.5 and $2, \sigma_{Y}{ }^{2}$ and $\sigma_{z}{ }^{2}$ are here, respectively, the lateral and vertical dispersion from a point source. In these formulaes, however, the self-induced turbulence behind the obstacle must, in contrast to the case with Eq. (12), play an important role.

\section{CONCLUSION}

An alternative method to the virtual source concept for calculating dispersion from a finite line source has been formulated on the basis of statistical theory, involving only few restrictions. We find that the composite dispersion from a cross-wind oriented continuous line source car. be expressed by

$$
\left\langle D^{2}(t)\right\rangle=\Sigma^{2}+\left\langle\tilde{y}^{2}(t)\right\rangle
$$

where $\Sigma^{2}$ is the second moment of the source distribution function and $\left\langle\tilde{y}^{2}(t)\right\rangle$ is the dispersion from a single point source in homogeneous and stationary turbulence. The maximum relative error introduced by use of the virtual source concept is typically found to be about 208 , hence the dispersion model in $\mathrm{Eq}$. (12) may be recommended in favour of the virtual source concept, especially since its use does not require any additional information. 


\section{ACKNOWLEDGEMENTS}

The authors are indebted to Drs. L. Kristensen and J. Hojstrup for many useful discussions. An improvement suggested by Dr. F. Gifford is gratefully acknowledged.

5. REFERENCES

PASOUILL, F., 1974: Atmospheric Diffusion, 2nd ed., J. Wiley and Suns, New York, 429 pp.

SLADE, D.H., 1968: Meteorology and Atomic Energy, N.S. Atomic Energy Commision, TID 24190, 445 PP.

SUTTON, O.G., 1932: A theory of eddy diffusion in the atmosphere, Proc. Roy. Soc. (London), Ser. A, 135, 143-165.

TAYLOR, G.I., 1921: Diffusion by continuous movements. Procedings of the London Mathematical Society, Series 2, 20, 196-202. 


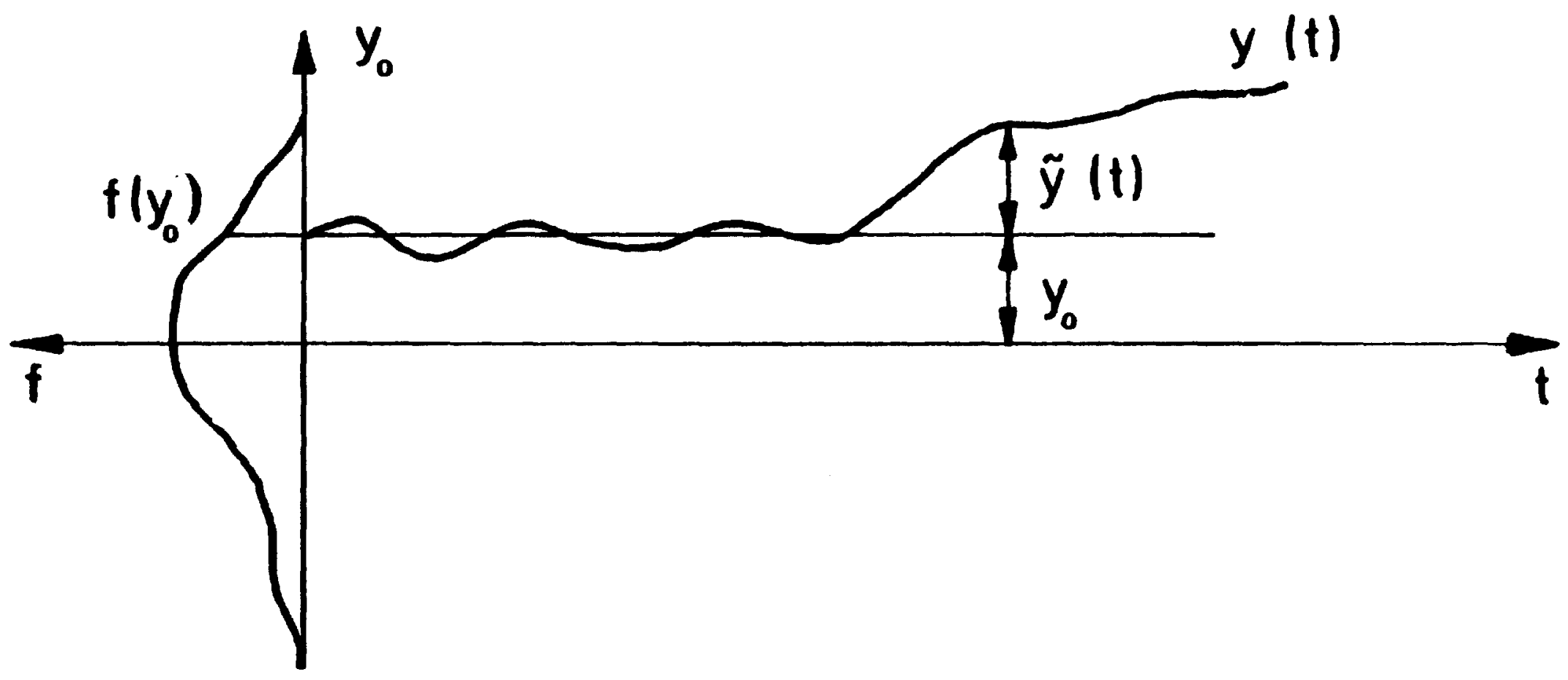

Fig. 1. A finite continuous line source emitting polutant with source strength $f\left(y_{0}\right)$ as function of lateral position $y_{0}$. Also shown is a trajectory $y(t)$ of a particle, reloased at $y_{0}$ at time $t=0$. 


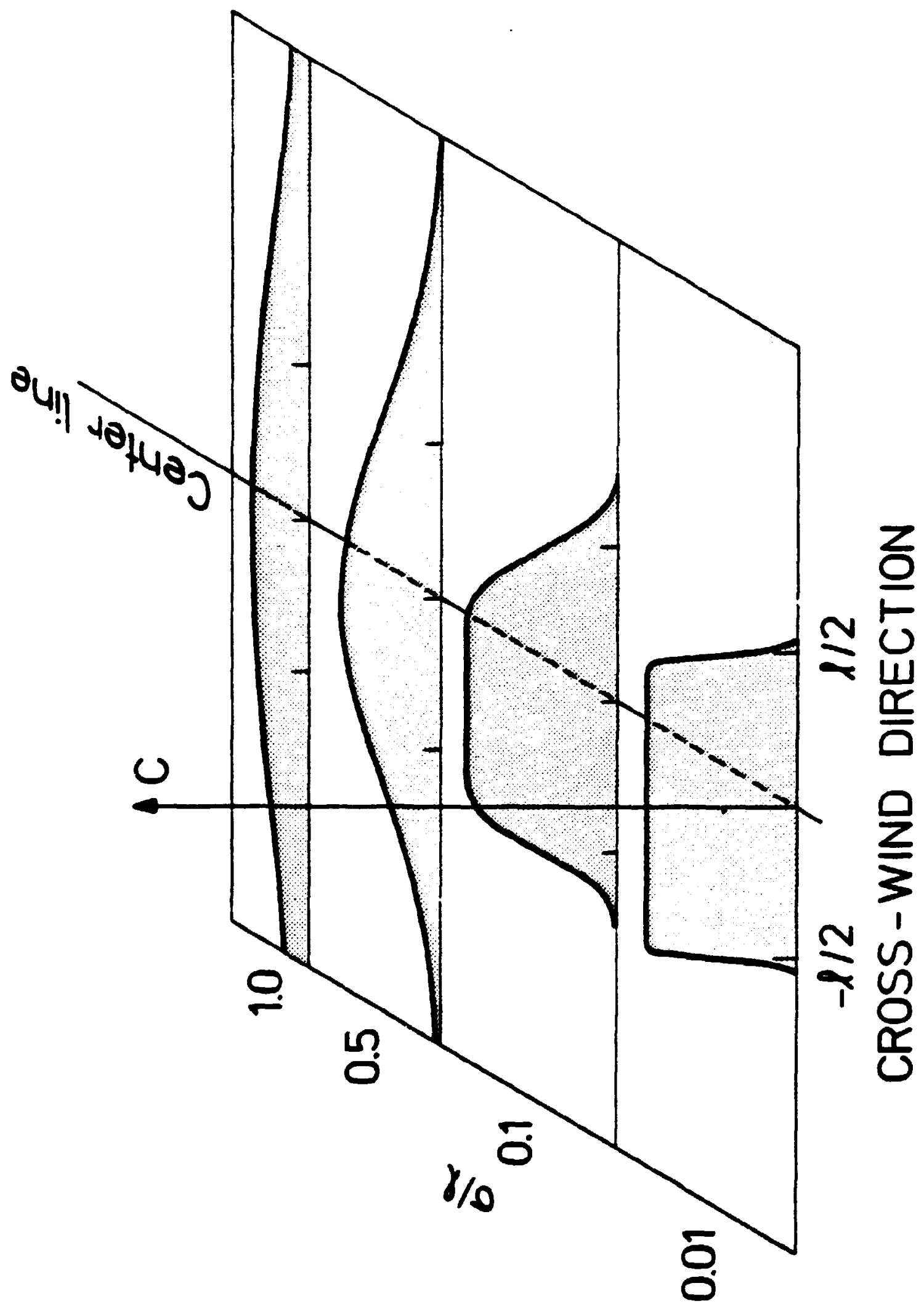

Fig. 2. Cross-wind concentration distributions for different ratios of the Gaussian point source dispe 3 ion $\sigma$ to the width $\ell$ of an rectangular distributed 1 ine source. Note that $z=\sqrt{12 \varepsilon}$ for the source distribution considered. 


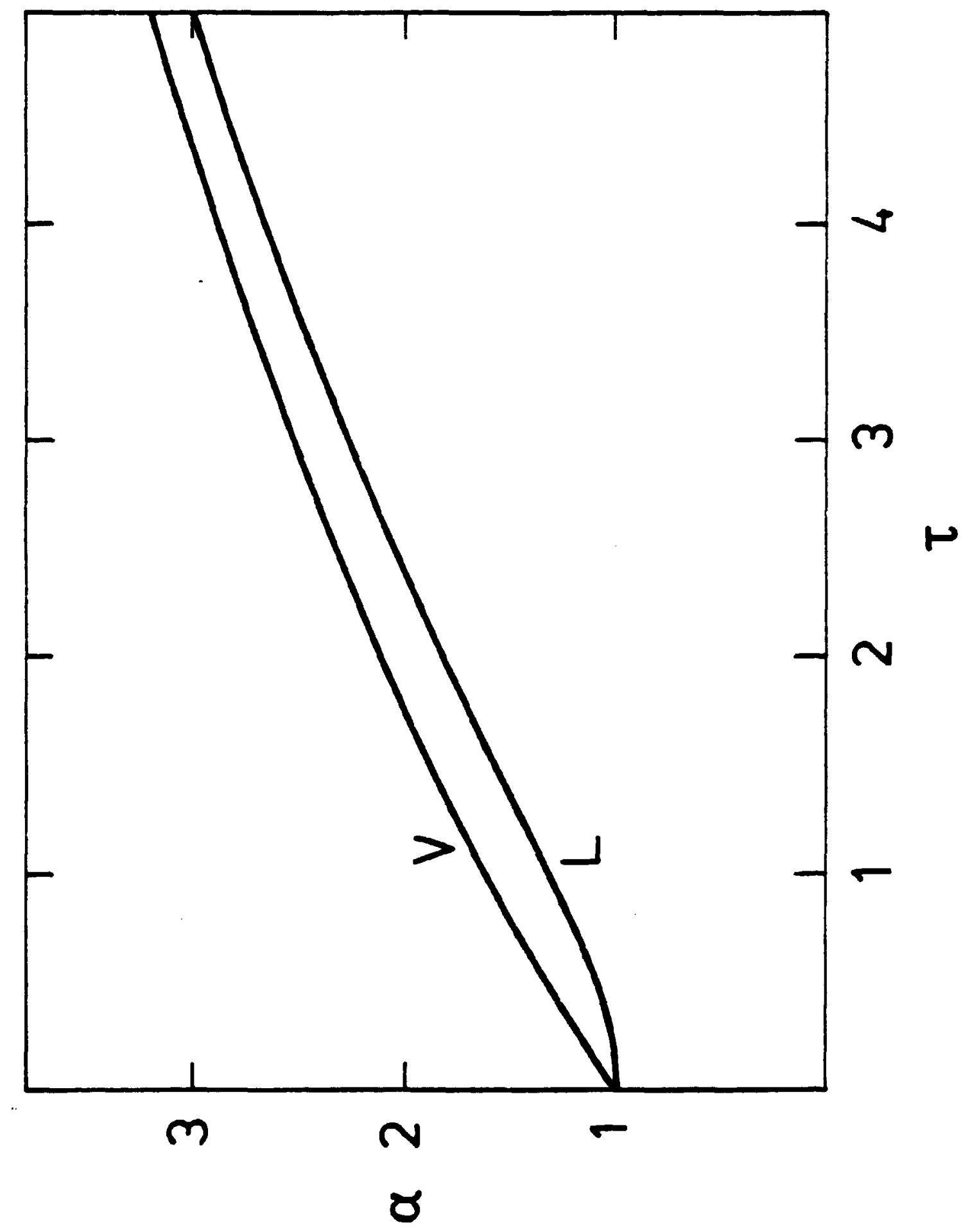

Eig. 3. Dimension less dispersion $\alpha=\left\langle D^{2}\right\rangle^{\frac{1}{2}} /\left\langle v^{\prime 2}\right\rangle^{\frac{t^{2}}{t_{1}}}$ for the virtual source: $V,(E q, 22)$ and for the line source: $L,(E q, 24)$ as function of dimensionless time of trave $1 \tau=t / t$. The standard deviation of the source distribution $\varepsilon$ equals $\left\langle v^{\prime 2}\right\rangle \cdot t_{1}$ in this case, i.e. $\Sigma^{\prime}=1$. 
On the finite line source problem in

Department or group diffusion theory Physics Dept.

T. Mikkelsen, I. Troen, and S.E. Larsen

17 pages + tables + illustrations

Abstract

A simple formula for calculating dispersion from

a continuous finite line source, placed at right angles to the mean wind direction, is derived on the basis of statistical theory-Comparison is made with the virtual source concept usually used and this is shown to be correct only in the limit where the virtual time 1 ag $T_{V}$ is small compared to the timescale of the turbulence $t_{1}$.

Availajle on request from Risq Library, Ris National Laboratory (Riso Bibliotek), Forsegsanlag Rise), DK-4000 Roskilde, Dennark

Telephone: (03) 371212 , ext. 2262. Telex: 43116 